\author{
JOANNA CHWASZCZ ${ }^{\mathrm{a}}$ \\ RAFAŁ P. BARTCZUK ${ }^{\mathrm{a}}$ \\ IWONA NIEWIADOMSKA ${ }^{\mathrm{a}}$ \\ STEVAN E. HOBFOLL ${ }^{\mathrm{b}}$ \\ AGNIESZKA PALACZ-CHRISIDIS ${ }^{\mathrm{a}}$ \\ ${ }^{a}$ Institute of Psychology, John Paul II Catholic University of Lublin, Poland \\ b STAR: Stress, Anxiety, and Resilience Consultants
}

\title{
THE POLISH ADAPTATION OF THE STRATEGIC APPROACH TO COPING SCALE
}

\begin{abstract}
The Strategic Approach to Coping Scale (SACS) is a tool designed to measure coping strategies in terms of the Multiaxial Model of Coping. The aim of this article is to present our work towards adapting the SACS to the Polish cultural context. The Polish translation of this measure and the Rotter Incomplete Sentence Blank were applied to 1,074 Poles from 11 sample groups at risk of social exclusion. Principal component analysis performed on the data showed six components rather than the original nine. Second-order factor analysis carried out on the subscale scores revealed three factors partially consistent with the original theoretical assumptions. Convergences and discrepancies of the resulting structure versus the original one are discussed, along with reliability and the preliminary theoretical validity of the method.
\end{abstract}

Keywords: coping strategies; Multiaxial Model of Coping; Strategic Approach to Coping Scale; marginalization.

Correspondence concerning this article should be addressed to JOANNA CHWASzCZ, PhD, Institute of Psychology, John Paul II Catholic University of Lublin, al. Racławickie 14 (room C-441), 20-950 Lublin, Poland; email: chwaszcz@kul.pl; ORCID: https://orcid.org/0000-00017068-4696; RAFAE P. BARTCZUK, ORCID: https://orcid.org/0000-0002-0433-7327; IWONA NIEWIADOMSKA, ORCID: https://orcid.org/0000-0002-0244-2748; STEVAN E. HobFOLL, ORCID: https://orcid.org/0000-0003-4136-0929; AGNIESZKA PALACZ-CHRISIDIS, ORCID: https://orcid.org/ 0000-0003-1253-8839.

This research was partially supported by grant POKL.01.02.00-00-016/12-00 from the European Social Fund, awarded to the John Paul II Catholic University of Lublin Development Foundation, and realized under the direction of Joanna Chwaszcz. 


\section{INTRODUCTION}

The Multiaxial Model of Coping, incorporating social and cultural aspects of coping behaviors, was developed by Stevan Hobfoll and colleagues (Dunahoo et al., 1998; Hobfoll, 1998; Hobfoll et al., 1994; Monnier et al., 1998). Initially, the model consisted of two axes: the active-passive dimension and the prosocial-antisocial dimension (Hobfoll et al., 1994). The distinguished axes are not fully independent - the model does not provide for passive prosocial strategies, because it is seen as impossible to be prosocial and yet passive as social activity requires actions (Hobfoll, 1998; Hobfoll et al., 2003). After theoretical and empirical considerations, the direct-indirect axis, reflecting cultural aspects of coping behaviors, was added. As a result, the model permits a broader application across individualist and collectivist cultures than nearly all other models, which are based on individualistic cultural assumptions (Geller et al., 2009; Hobfoll et al., 2003).

Based on the Multiaxial Model of Coping, the researchers developed the Strategic Approach to Coping Scale (SACS) to assess coping strategies (Hobfoll et al., 1994). The items of SACS were generated on the basis of common proverbs, idioms, and strategies (Hobfoll et al., 1994). The authors identified nine subscales of the scale: (1) Assertive Action, (2) Social Joining, (3) Seeking Social Support, (4) Instinctive Action, (5) Avoidance, (6) Antisocial Action, (7) Aggressive Action, (8) Cautious Action, and (9) Indirect Action (Dunahoo et al., 1998). The SACS has a dispositional and situational version, each consisting of 52 items (Monnier et al., 1998). The subscales of SACS are grouped in three second-level factors: (1) Active Antisocial Coping, comprising Aggressive Action, Instinctive Action, and Antisocial Action; (2) Active Prosocial Coping, comprising Social Joining, Seeking Social Support, and Cautious Action; and (3) Active-Passive (asocial) Coping, constituted of Avoidance and Assertive Action (with the opposite sign) (Dunahoo et al., 1998; Hobfoll, 1998).

The approach proposed by Hobfoll and colleagues has been noticed by researchers from many countries around the world, probably because this concept is multidimensional and captures stress management in the context of resource distribution. Also, numerous translations and adaptations of the SACS appeared worldwide. The scoping review of the existing SACS translations (Bartczuk et al., 2020) showed that its structure differs cross-culturally in terms of the number and content of the factors. However, these authors distinguish factors that are relatively cross-culturally stable (Seeking Social Support, Avoidance, Assertive Action, Instinctive Action, and Aggressive Action or/and/combined 
Antisocial Action), and those more sensitive to cultural context (Social Joining, Cautious Action, Indirect Action, Aggressive Action, and Antisocial Action). The second-order factors are more interculturally stable, and particularly the activepassive axis has a robust empirical justification. Concerning the social axis, one of two solutions can be expected: either two factors (active-prosocial and activeantisocial) or a single factor (prosocial vs. antisocial). To date, there has been little empirical support that the SACS is a good operationalization of the indirectdirect axis of coping (Bartczuk et al., 2020).

To date, in Poland there are three translations of the SACS with a similar methodological status: (1) an adaptation by Zabielski and Polityńska, used in some research (e.g., Bernat \& Krzyszkowska, 2017; Łosiak, 2008); (2) translation of the SACS items made by Kacmajor in the Polish edition of Hobfoll's Stress, Culture, and Community (Hobfoll, 2006), and used by some researchers (e.g., Chodak \& Barwiński, 2010); and (3) the SACS-S translation prepared at the Catholic University of Lublin by Niewiadomska's team and used in numerous studies (Chwaszcz et al., 2016; Jachowicz et al., 2015; Łącka et al., 2015; Niewiadomska et al., 2016; Pietras et al., 2015; Tyrka et al., 2015). In all Polish translations, the original scoring key was used, and only the reliability of the subscales (or their range) was provided in publications. To the best of our knowledge, there is no documented attempt to confirm the structure of any of the Polish translations of the SACS.

\section{STRATEGIC COPING AND PERSONAL ADJUSTMENT}

The underlying assumption of the Multiaxial Model of Coping is that active and avoidant coping strategies are not socially neutral, and a failure to take this fact into account may distort conclusions about their positive and negative effects (Hobfoll, 1998). Prosocial coping involves a positive use of social resources. In contrast, antisocial coping includes behaviors that, while satisfying the individual's needs, might be detrimental to those in their surroundings. The term "antisocial" is used here not in the psychopathological sense but to designate behaviors that may indeed be harmful to others or using others and even exploiting them for personal gain (Monnier et al., 1996). From the theoretical point of view, the most adaptive are active-prosocial strategies, the least adaptive is avoidant coping, while the effectiveness of active-antisocial strategies depends on the situational context. 
The relationship between adaptation and preferred coping strategies was covered by numerous studies involving various groups: students (Heffer \& Willoughby, 2017; Kozhukhar, 2017; Smith \& Yang, 2017), cancer patients (Kaliampos \& Roussi, 2017; Knowles et al., 2017; Zadeh et al., 2018), depression patients (Drapeau et al., 2017), multiple sclerosis patients (Grech et al., 2018), people discriminated against on racial grounds (Levy et al., 2016; Park et al., 2018), and women with HIV/AIDS (Seffren et al., 2018).

Past research indicates that prosocial coping behaviors are related to better psychological functioning (Dunahoo et al., 1998; Hobfoll et al., 1994, 2003; Monnier et al., 1998) and that active, individualistic coping behaviors have a positive effect on psychological functioning (Carver et al., 1989; Folkman, 1997; Osowiecki \& Compas, 1999). In her study on a group of 105 psychology students, Kozhukhar (2017) showed that strategies such as seeking social support and positive reappraisal correlate positively with personal adjustment. In a highly collectivist group of Ethiopian emigrants, the frequent use of Social Joining was significantly associated with proper psychological functioning. On the other hand, the frequent use of Avoidance, passivity, and antisocial coping strategies was significantly associated with the incidence of psychopathological symptoms (Finklestein et al., 2012).

Smith and Yang (2017) conducted studies in a group of 1,538 nursing students in China. The results of these studies indicate that active coping with stress is accompanied by a higher sense of life quality and personal adjustment. Heffer and Willoughby (2017), in their studies on a group of 1,132 students, showed that the use of more positive coping strategies leads to better personal adjustment. In turn, the use of negative coping strategies is a predictor of depressive symptoms and ineffective emotional regulation. Kaliampos and Roussi (2017) conducted studies on a group of 87 cancer patients. They examined the relationship between the coping strategies used and personal adjustment and quality of life. The use of religious strategies and the strategy of positive reappraisal correlated positively with positive adaptation and high quality of life. Knowles et al. (2017) conducted a study in 2017 on a group of 131 patients with intestinal diseases, in which they concluded that the use of non-adaptive coping strategies cooccurs with reduced adaptation. Zadeh et al. (2018) studied 70 cancer patients. They demonstrated that using active coping strategies, with supportive therapy based on these, correlates positively with positive personal adjustment. Drapeau et al. (2017) studied patients with depression. The results of these studies showed that strategies such as information seeking and problem solving correlate with better adaptation. Grech et al. (2018) conducted studies on a group of 107 multi- 
ple sclerosis patients. The results were as follows: emotional preoccupation correlated positively with low social adjustment, while positive reappraisal turns out to be the most effective strategy leading to a personal adjustment of the subjects. In those who are discriminated against on racial grounds, the use of aggressive coping strategies coincided with personal maladjustment (Levy et al., 2016; Park et al., 2018), while social support-seeking correlated positively with better personal adjustment in the situation of racial discrimination. A study by Seffren et al. (2018), conducted among 288 women with HIV/AIDS, showed that social support seeking co-occurred with positive personal adjustment. Studies using the SACS conducted in a sample of 60 Romanian healthcare professionals also showed that the intensity of stress, depression, and anxiety in the study group was significantly correlated with the preference of three remedial strategies: Avoidance, Assertive Action, and Seeking Social Support. Lower levels of stress, depression, and anxiety co-occurred with higher levels of assertive action and social support seeking. In contrast, greater severity of these syndromes correlated with a higher level of avoidance (Crăciun et al., 2015). Studies carried out using the Polish adaptation of the SACS in a group of 102 subjects (students and those using psychological counseling) found two negative links: between the intensity of emotional self-aggression and assertive action, and between the occurrence of physical self-aggression and cautious action (Chodak \& Barwiński, 2010).

\section{THIS STUDY}

This study presents our proposed adaptation of the SACS to the Polish cultural context. We carried out our research on a group of individuals threatened by social marginalization. The Multiaxial Model of Coping seems especially valuable for examining people with low levels of own resources (Chwaszcz et al., 2019). It assumes that the choice of the coping behavior depends on the level of resources but also on their availability in the environment. A cultural adaptation of the SACS used for a group of people experiencing a situation with objectively recognized difficulties (e.g., homelessness, imprisonment, under-age motherhood) will ensure that a given study encompasses a broad spectrum of behaviors in situations of varying difficulty, taking into account available individual and environmental resources.

The aims of this study are as follows: (1) to explore the first-level structure of the proposed Polish adaptation using a sample of Polish adults at risk of social exclusion; (2) to explore the second-level factors; and (3) to examine the validity 
of the scale by correlating it with the measure of personal adjustment based on a different methodology than the SACS.

Based on the review by Bartczuk et al. (2020), we expect that a Polish adaptation of the scale will reproduce Seeking Social Support, Avoidance, Assertive Action, Instinctive Action, and some type of Aggressive Action or/and Antisocial Action. As regards the second-order structure, the identification of an ActivePassive factor, based on Avoidance and Assertive Action, is expected. We also expect either two social coping factors: active-prosocial (with Social Joining and Seeking Social Support) and active-antisocial (based on Aggressive Action and Antisocial Action), or one factor with two poles: prosocial (Social Joining and Seeking Social Support) vs. antisocial (Aggressive Action and Antisocial Action). Also, following the Multiaxial Model of Coping, we hypothesized that active-prosocial coping is positively related to personal adjustment and that there are gender differences in the relationship between coping and adjustment.

\section{METHOD}

\section{Participants}

Data were collected in 11 samples at risk of social exclusion (total $N=1,074)$. The samples included: those with an experience of prostitution, teenage mothers, residents of single mothers' homes, homeless men, former prisoners, juveniles in detention centers, orphanage alumni, euro-orphans, youths from families with alcohol problems, youths from large families, and substance abusers. Informed consent was obtained from all individual adult participants included in the study. The age and gender of the subjects in all the samples are shown in Table 1.

The study was carried out in assistance and resocialization institutions across Poland, including homeless shelters, single mothers' homes, municipal social welfare centers, crisis intervention centers, correctional centers, orphanages, sociotherapy centers, and therapeutic centers. Trained interviewers (30 individuals) personally carried out the surveys in designated institutions. The study sites were selected based on the availability and consent of the authorities of each facility, after prior contact by telephone or letter. The study was anonymous, and all respondents voluntarily agreed to participate. The nature of the study group and the challenging methods made it necessary to run the surveys one on one. 
Table 1. Gender and Age of Subjects in 11 Samples

\begin{tabular}{|c|c|c|c|c|c|c|c|}
\hline \multirow{2}{*}{ Group } & \multirow[b]{2}{*}{$n$} & \multirow[b]{2}{*}{$\begin{array}{c}\% \\
\text { of total }\end{array}$} & \multirow{2}{*}{$\begin{array}{c}\text { Gender } \\
\% \\
\text { of females }\end{array}$} & \multicolumn{4}{|c|}{ Age } \\
\hline & & & & $M$ & $S D$ & $\min$ & $\max$ \\
\hline People with experience of prostitution & 64 & $6.0 \%$ & $85.7 \%$ & 27.6 & 7.90 & 16 & 51 \\
\hline Teenage mothers & 86 & $8.0 \%$ & $100.0 \%$ & 20.3 & 2.37 & 16 & 25 \\
\hline Inhabitants of houses for single mothers & 74 & $6.9 \%$ & $100.0 \%$ & 31.4 & 9.94 & 16 & 58 \\
\hline Homeless men & 110 & $10.2 \%$ & $0.0 \%$ & 49.1 & 12.06 & 18 & 76 \\
\hline Former prisoners & 34 & $3.2 \%$ & $13.3 \%$ & 33.8 & 12.94 & 17 & 65 \\
\hline Juveniles in detention centres & 145 & $13.5 \%$ & $44.3 \%$ & 18.5 & 3.31 & 16 & 28 \\
\hline Graduates of orphanages & 122 & $11.4 \%$ & $57.3 \%$ & 18.3 & 2.03 & 16 & 25 \\
\hline Euro-orphans & 117 & $10.9 \%$ & $62.1 \%$ & 20.8 & 2.86 & 16 & 25 \\
\hline $\begin{array}{l}\text { Youths from families with alcohol } \\
\text { problems }\end{array}$ & 131 & $12.2 \%$ & $55.0 \%$ & 20.6 & 2.68 & 16 & 25 \\
\hline Youths from large families & 60 & $5.6 \%$ & $77.2 \%$ & 22.2 & 1.75 & 18 & 25 \\
\hline People misusing substances & 131 & $12.2 \%$ & $55.8 \%$ & 34.3 & 11.82 & 16 & 66 \\
\hline Total & 1,074 & $100 \%$ & $57.8 \%$ & 26.3 & 11.95 & 16 & 76 \\
\hline
\end{tabular}

Note. $n, M, S D$, $\min$, and $\max$ are used to represent the number of subjects in the group, mean, standard deviation, minimum value, and maximum value, respectively.

Out of 1,074 completed questionnaires, those in which the respondent did not respond to $20 \%$ or more SACS items were excluded. In this way, 32 participants were rejected, and ultimately 1,042 results were finally accepted for the analysis. Those excluded individuals did not differ in any socio-demographical variable from the rest of the participants. The remaining missing responses to individual items were imputed using a method based on canonical variates, implemented in the Hmisc package (Harrel Jr, et al., 2018). 597 missing responses were supplemented in this way, which represented $1 \%$ of all responses.

Statistical analyzes were performed using the Amos (Arbuckle, 2016) and $\mathrm{R}$ statistical environment (R Core Team, 2018) with Hmisc (Harrel Jr. et al., 2018), psych (Revelle, 2018), nlme (Pinheiro et al., 2018), and psycho (Makowski, 2018) packages.

\section{MEASURES}

The Polish translation of the SACS (SACS-PL). The translation is based on the situational version of the SACS developed by Hobfoll and colleagues (Monnier et al., 1998), consisting of 52 items with a 5-point response format, 
ranging from 1 (= Didn't do this at all) to 5 (= Did this a lot). When answering the questions, respondents refer to their generally difficult life situation in which they have recently found themselves. We used Niewiadomska's team's version of the scale, developed by translating the original items and then determining their final wording by a panel of expert psychologists, based on the meaning of the SACS subscales.

The Rotter Incomplete Sentences Blank (RISB). The RISB sentence completion projective technique (Rotter et al., 1992) was used in the Polish adaptation by Jaworowska and Matczak (2003) to assess the level of personal maladjustment. RISB is a 40-item instrument consisting of brief sentence stems, such as "I like..." The subject is asked to complete these sentences to express their feelings. Responses are scored based on the absence or presence of conflict. Negative responses are scored from 4 to 6 , and a neutral response scores 3, while positive responses receive from 0 to 2 . Guidelines for assigning scores to responses are provided in the RISB manual. Total scores range from 0 to 240 . The higher the result, the higher the maladjustment.

The basis for the Polish adaptation of the RISB was the second original edition published in 1992. The instrument has the advantages of projective techniques (the free nature of expression, a high degree of concealment of the purpose of the study), and the advantages of objective methods (reliability of the assessment and the quantitative result). The psychometric properties of the Polish version of RISB are well-proven. The agreement of assessments of the same protocols made by competent referees, measured by Spearman's correlation coefficient, was .96 (Jaworowska \& Matczak, 2003). Validity studies, conducted using the method of differences between contrast groups, showed that individuals in a situation involving social adjustment problems (prisoners, abused women, depression patients, unemployed) achieved a significantly lower level of adaptation than those in the standardization sample (Jaworowska \& Matczak, 2012). In the present study, Cronbach's $\alpha$ for the RISB was .80 .

\section{RESULTS}

\section{SACS-PL Structure}

The first aim of the present study was to examine the structure of the SACS-PL. For this purpose, we grouped the items (first-order analysis) and on this basis we constructed subscales, which we then grouped again (second-order analysis). 


\section{First-Order Structure Analysis}

To find first-level factors, the data were analyzed using PCA with varimax rotation, utilized in the development of the original version of the SACS, as well as in the majority of its adaptations. Preliminary analysis of the data showed their relevance for the intended analyses $(K M O=.90$; the smallest item $M S A=.83$; Bartlett test: $\left.\chi^{2}(1326)=13949.46, p<.001\right)$. Nine subscales suggested by Hobfoll and his colleagues (Dunahoo et al., 1998) could not be fully reproduced. The Kaiser criterion (used in almost all existing adaptations of the SACS) showed ten components to extract. In the present study, we used a parallel analysis as the final decision-making criterion (Timmerman \& Lorenzo-Seva, 2011). Six components, indicated by the parallel analysis, accounted for $40 \%$ of the variance (Table 2). With the criterion of component loading greater than 0.40 , in the resulting solution, 45 items comprised one component, while seven items did not reach the criterion of any of the components.

Table 2. Results of Principal Component Analysis with Varimax Rotation of SACS-PL $(N=1,042)$

\begin{tabular}{|c|c|c|c|c|c|c|c|c|c|}
\hline $\begin{array}{l}\text { Item } \\
\text { no. }\end{array}$ & Content & $\mathrm{PC} 1$ & PC2 & PC3 & PC4 & PC5 & PC6 & $\begin{array}{l}\text { Subscale } \\
\text { PL }\end{array}$ & $\begin{array}{l}\text { Subscale } \\
\text { US }\end{array}$ \\
\hline 39 & $\begin{array}{l}\text { "I acted quickly to put others at a disad- } \\
\text { vantage." }\end{array}$ & .69 & .10 & .09 & .04 & -.05 & -.04 & $\begin{array}{l}\text { Dominating } \\
\text { Action }\end{array}$ & $\begin{array}{l}\text { Antisocial } \\
\text { Action }\end{array}$ \\
\hline 36 & "I quickly asserted my dominance." & .67 & .18 & .06 & .04 & .03 & -.02 & $\begin{array}{l}\text { Dominating } \\
\text { Action }\end{array}$ & $\begin{array}{l}\text { Antisocial } \\
\text { Action }\end{array}$ \\
\hline 44 & $\begin{array}{l}\text { "I looked for others' weaknesses and used } \\
\text { them to my advantage." }\end{array}$ & .65 & -.01 & .10 & .00 & .10 & .03 & $\begin{array}{l}\text { Dominating } \\
\text { Action }\end{array}$ & $\begin{array}{l}\text { Antisocial } \\
\text { Action }\end{array}$ \\
\hline 31 & $\begin{array}{l}\text { "I moved aggressively; often if you get } \\
\text { another off-guard, things will work to your } \\
\text { advantage." }\end{array}$ & .62 & .18 & .14 & .05 & -.11 & .03 & $\begin{array}{l}\text { Dominating } \\
\text { Action }\end{array}$ & $\begin{array}{l}\text { Aggressive } \\
\text { Action }\end{array}$ \\
\hline 37 & $\begin{array}{l}\text { "My only choice was to be a little manipu- } \\
\text { lative and work around people." }\end{array}$ & .62 & .14 & .14 & .02 & -.09 & .00 & $\begin{array}{l}\text { Dominating } \\
\text { Action }\end{array}$ & $\begin{array}{l}\text { Indirect } \\
\text { Action }\end{array}$ \\
\hline 16 & $\begin{array}{l}\text { "I counterattacked and caught others } \\
\text { off-guard." }\end{array}$ & .60 & .08 & .10 & .00 & .08 & .21 & $\begin{array}{l}\text { Dominating } \\
\text { Action }\end{array}$ & $\begin{array}{l}\text { Antisocial } \\
\text { Action }\end{array}$ \\
\hline 19 & $\begin{array}{l}\text { "I looked out for my own best interests } \\
\text { even if it means hurting others." }\end{array}$ & .55 & .04 & .17 & -.16 & .12 & .12 & $\begin{array}{l}\text { Dominating } \\
\text { Action }\end{array}$ & $\begin{array}{l}\text { Antisocial } \\
\text { Action }\end{array}$ \\
\hline 21 & $\begin{array}{l}\text { "Others needed to feel they are the boss, } \\
\text { so I worked around them to get things } \\
\text { done." }\end{array}$ & .54 & -.02 & .28 & -.06 & -.21 & .16 & $\begin{array}{l}\text { Dominating } \\
\text { Action }\end{array}$ & $\begin{array}{l}\text { Indirect } \\
\text { Action }\end{array}$ \\
\hline 34 & $\begin{array}{l}\text { "I let others think they are in control, but } \\
\text { kept my own hands firmly on the wheel." }\end{array}$ & .48 & .25 & .16 & .03 & -.25 & -.01 & $\begin{array}{l}\text { Dominating } \\
\text { Action }\end{array}$ & $\begin{array}{l}\text { Indirect } \\
\text { Action }\end{array}$ \\
\hline 4 & $\begin{array}{l}\text { "I tried to be in control, but I let others } \\
\text { think they were still in charge." }\end{array}$ & .41 & -.11 & .03 & .09 & -.29 & .38 & $\begin{array}{l}\text { Dominating } \\
\text { Action }\end{array}$ & $\begin{array}{l}\text { Indirect } \\
\text { Action }\end{array}$ \\
\hline
\end{tabular}




\begin{tabular}{|c|c|c|c|c|c|c|c|c|c|}
\hline 52 & $\begin{array}{l}\text { "I directly addressed the situation, and } \\
\text { didn't back away from the problem." }\end{array}$ & -.01 & .66 & -.13 & .18 & -.21 & .08 & $\begin{array}{l}\text { Assertive } \\
\text { Action }\end{array}$ & $\begin{array}{l}\text { Assertive } \\
\text { Action }\end{array}$ \\
\hline 49 & "I was firm; held my ground." & .15 & .66 & -.06 & .01 & -.09 & .13 & $\begin{array}{l}\text { Assertive } \\
\text { Action }\end{array}$ & $\begin{array}{l}\text { Aggressive } \\
\text { Action }\end{array}$ \\
\hline 51 & $\begin{array}{l}\text { "I was strong and forceful, but avoided } \\
\text { harming others." }\end{array}$ & .04 & .63 & .01 & .12 & -.19 & -.03 & $\begin{array}{l}\text { Assertive } \\
\text { Action }\end{array}$ & $\begin{array}{l}\text { Assertive } \\
\text { Action }\end{array}$ \\
\hline 45 & $\begin{array}{l}\text { "I took the bull by the horns; adopted } \\
\text { a take-charge attitude." }\end{array}$ & .25 & .58 & -.04 & .13 & -.02 & .10 & $\begin{array}{l}\text { Assertive } \\
\text { Action }\end{array}$ & $\begin{array}{l}\text { Aggressive } \\
\text { Action }\end{array}$ \\
\hline 50 & "I was assertive and got my needs met." & .22 & .58 & .01 & .08 & -.05 & -.05 & $\begin{array}{l}\text { Assertive } \\
\text { Action }\end{array}$ & $\begin{array}{l}\text { Assertive } \\
\text { Action }\end{array}$ \\
\hline 48 & $\begin{array}{l}\text { "I relied on my own judgement because } \\
\text { only I have my best interests at heart." }\end{array}$ & .15 & .49 & .23 & -.12 & -.06 & .09 & $\begin{array}{l}\text { Assertive } \\
\text { Action }\end{array}$ & $\begin{array}{l}\text { Instinctive } \\
\text { Action }\end{array}$ \\
\hline 26 & "I just worked harder; applied myself." & -.04 & .48 & -.11 & .24 & -.30 & .15 & $\begin{array}{l}\text { Assertive } \\
\text { Action }\end{array}$ & $\begin{array}{l}\text { Assertive } \\
\text { Action }\end{array}$ \\
\hline 35 & "I went with my intuition." & .07 & .40 & .24 & .22 & .15 & .04 & $\begin{array}{l}\text { Assertive } \\
\text { Action }\end{array}$ & $\begin{array}{l}\text { Instinctive } \\
\text { Action }\end{array}$ \\
\hline 15 & $\begin{array}{l}\text { "I retreated; avoided contact until the } \\
\text { problem blew over." }\end{array}$ & .15 & -.09 & .65 & .01 & .00 & -.03 & Avoidance & $\begin{array}{l}\text { Assertive } \\
\text { Action }\end{array}$ \\
\hline 22 & "I backed off and just let the smoke clear." & .11 & -.03 & .62 & .05 & -.18 & -.09 & Avoidance & Avoidance \\
\hline 32 & $\begin{array}{l}\text { "It wasn't getting worse, so I avoided the } \\
\text { whole thing." }\end{array}$ & .22 & .08 & .61 & .00 & -.06 & -.17 & Avoidance & Avoidance \\
\hline 33 & $\begin{array}{l}\text { "I got out of the situation; when problems } \\
\text { arise, it's usually a sign of worse to come." }\end{array}$ & .29 & .03 & .60 & -.05 & .02 & -.10 & Avoidance & $\begin{array}{l}\text { Assertive } \\
\text { Action }\end{array}$ \\
\hline 47 & $\begin{array}{l}\text { "I focused on something else and let the } \\
\text { situation resolve itself." }\end{array}$ & .15 & -.01 & .59 & .11 & .01 & .03 & Avoidance & Avoidance \\
\hline 7 & $\begin{array}{l}\text { "I avoided dealing with the problem; } \\
\text { things like this often go away on their } \\
\text { own." }\end{array}$ & .12 & -.05 & .56 & -.07 & .07 & .12 & Avoidance & Avoidance \\
\hline 25 & $\begin{array}{l}\text { "I thought I'd probably feel bad, but } \\
\text { there is not much you can do about this } \\
\text { sort of thing." }\end{array}$ & .02 & .11 & .56 & .08 & -.15 & .07 & Avoidance & $\begin{array}{l}\text { Assertive } \\
\text { Action }\end{array}$ \\
\hline 10 & $\begin{array}{l}\text { "I moved on to other things; there's little } \\
\text { hope for such situations getting better." }\end{array}$ & .06 & -.07 & .54 & .04 & .05 & .20 & Avoidance & $\begin{array}{l}\text { Assertive } \\
\text { Action }\end{array}$ \\
\hline 20 & $\begin{array}{l}\text { "I did something to help avoid thinking } \\
\text { about the problem." }\end{array}$ & -.05 & .11 & .52 & .07 & -.13 & .24 & Avoidance & Avoidance \\
\hline 27 & $\begin{array}{l}\text { "I held back, as it was better to wait until } \\
\text { the smoke cleared before any action was } \\
\text { taken." }\end{array}$ & .01 & .02 & .50 & .14 & -.28 & -.07 & Avoidance & Avoidance \\
\hline 11 & "I depended on my gut-level reaction." & .28 & .09 & .41 & .08 & .18 & .30 & Avoidance & $\begin{array}{l}\text { Instinctive } \\
\text { Action }\end{array}$ \\
\hline 46 & $\begin{array}{l}\text { "I asked friends or family for their } \\
\text { opinions about my plan of action." }\end{array}$ & -.02 & .18 & .02 & .70 & -.07 & -.11 & $\begin{array}{l}\text { Seeking Social } \\
\text { Support }\end{array}$ & $\begin{array}{l}\text { Seeking Social } \\
\text { Support }\end{array}$ \\
\hline 28 & $\begin{array}{l}\text { "I went to someone for emotional } \\
\text { support." }\end{array}$ & -.05 & .08 & .02 & .66 & -.03 & -.08 & $\begin{array}{l}\text { Seeking Social } \\
\text { Support }\end{array}$ & $\begin{array}{l}\text { Seeking Social } \\
\text { Support }\end{array}$ \\
\hline 13 & "I turned to others for help." & .01 & .06 & .14 & .65 & -.05 & .03 & $\begin{array}{l}\text { Seeking Social } \\
\text { Support }\end{array}$ & $\begin{array}{l}\text { Seeking Social } \\
\text { Support }\end{array}$ \\
\hline 9 & $\begin{array}{l}\text { "I checked with family about what they } \\
\text { would do." }\end{array}$ & -.01 & -.02 & .00 & .59 & -.13 & -.09 & $\begin{array}{l}\text { Seeking Social } \\
\text { Support }\end{array}$ & $\begin{array}{l}\text { Seeking Social } \\
\text { Support }\end{array}$ \\
\hline
\end{tabular}


18 "I depended on myself but at the same $\quad$\begin{tabular}{lllllll}
\hline .04 & .11 & -.04 & $\mathbf{. 5 8}$ & -.18 & .14 Seeking Social Seeking Social
\end{tabular}

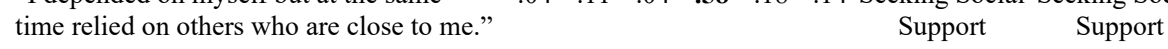

$\begin{array}{lllllllll}2 & \text { "I checked with friends about what they } & -.06 & .06 & -.05 & .57 & .04 & .24 & \text { Seeking Social Seeking Social }\end{array}$ would do." Support Support

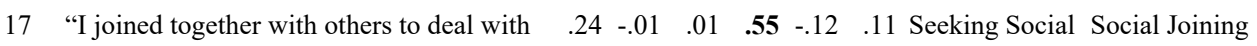
the situation together." Support

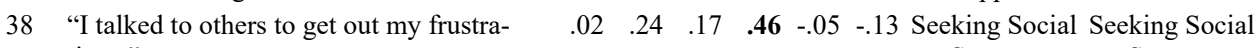
tions." Support Support

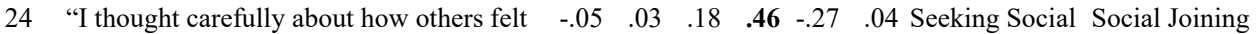
before deciding what to do."

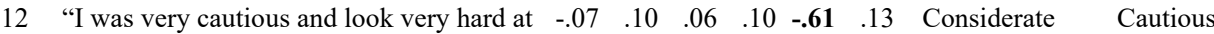
my options (better safe than sorry)."

"I did something to help calm down and,

only then, started problem-solving."

Action

Action

23 "I tried to help out others involved in the situation, as giving of yourself usually helps solve problems like this."

14 "I went forward but didn't use all my resources until I knew full well what I was up against."

3 "I acted fast; it is better to throw myself right into the problem."

Considerate

Cautious Action

Action

"I depended on myself and my personal strengths; it's not a good idea to depend on others."

6 "I trusted my instincts, not my thoughts."

$\begin{array}{llllllll}.06 & .22 & .09 & .32 & -.44 & .04 & \text { Considerate } & \text { Social Joining }\end{array}$ Action

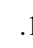

1 "I didn't give up, even when things look

$\begin{array}{llllll}-.07 & .070 & -.23 & .09 & -.27 & .39\end{array}$ their worst, because you can often turn things around."

8 "I mounted an all-out attack; was aggressive."

$\begin{array}{llllll}.33 & .00 & .26 & -.05 & .36 & .26\end{array}$

$\begin{array}{llllll}.08 & .18 & .27 & .12 & -.38 & -.03\end{array}$ Action

Cautious

Action thought there may have been a hidden agenda."

30 "I tried hard to meet others' wishes as this will really help the situation."

40 "I broke up the problem into smaller parts and deal with them one at a time."

41 "I tried to meet the needs of others who were involved."

42 "I followed my first impulse; things usually work out best that way."

Note. Factor loadings greater than .40 are bolded; PC1 to PC6 are used to represent the six components obtained in the analysis; the PL and US subscales are used to mark an item's subscale membership in the Polish and American versions, respectively. 
The components thus obtained were labeled: (1) Dominating Action, comprising ten items, including whole original subscales of Antisocial Action (five items) and Indirect Action (four items), and one item from Aggressive Action ("I moved aggressively; often if you get another off-guard, things will work to your advantage"); (2) Assertive Action, comprising eight items, including four out of five positively formulated Assertive Action items and two items from each of the subscales: Aggressive Action and Instinctive Action; (3) Avoidance, comprising 11 items, including the whole Avoidance subscale (six items), all negatively formulated Assertive Action items (four items) and one Instinctive Action item ("I depended on my gut-level reaction"); (4) Seeking Social Support-nine items: whole Seeking Social Support subscale, and two items from Social Joining; (5) Considerate Action, comprising four items from Cautious Action (three items), and one from Social Joining ("I tried to help out others involved in the situation because giving of yourself usually helps solve problems like this"); (6) Instinctive Action, comprising three items: one from Aggressive Action ("I acted fast; it is better to throw myself right into the problem") and two from the original Instinctive Action.

The main results of the analysis were as follows:

1) The American version contained nine subscales but the Polish adaptation contained six subscales. This is not surprising because the review of existing adaptations (Bartczuk et al., 2020) indicates that several identified subscales varied across cultures.

2) All the expected, relatively culturally stable subscales were reproduced in the Polish version. This is true for Seeking Social Support, Avoidance, Assertive Action, and Instinctive Action.

3) The culturally specific Dominating Action was obtained, which consists of Antisocial Action, Indirect Action, and one Aggressive Action item. This solution is similar to the Mexican version of the SACS, in which the three subscales were also combined into one factor (Pérez \& Gómez-Maqueo, 2007).

4) We also identified a Considerate Action subscale, in which, similarly to the German version (Schwarzer et al., 2003), Cautious Action is associated with certain aspects of Social Joining.

5) Aggressive Action was disintegrated.

6) Social Joining was not reproduced, and the items of this were incorporated into the Polish Seeking Social Support and Cautious Action.

7) Indirect Action was not reproduced as it was fully incorporated into Dominating Action. 


\section{Reliabilities and Intercorrelations of Subscales}

The basic descriptive statistics of the subscales scores, their reliability, and intercorrelations are presented in Table 3. Two coefficients were used for the reliability analysis: Cronbach's $\alpha$ and Guttman's $\lambda_{6}$.

Table 3. Descriptive Statistics and Intercorrelations of the Subscales of SACS-PL $(N=1,042)$

\begin{tabular}{lccccccccccc}
\hline \multicolumn{1}{c}{ Variable } & $k$ & $M$ & $S D$ & $\alpha$ & $\lambda_{6}$ & 1. & 2. & 3. & 4. & 5. & 6. \\
\hline 1. Dominating Action & 10 & 2.67 & 0.70 & .82 & .83 & & .41 & .51 & .10 & .21 & .55 \\
2. Assertive Action & 8 & 3.28 & 0.66 & .76 & .77 & .33 & & .17 & .41 & .66 & .53 \\
3. Avoidance & 11 & 2.93 & 0.65 & .81 & .82 & .42 & .13 & & .20 & .24 & .41 \\
4. Seeking Social Support & 9 & 3.21 & 0.71 & .79 & .79 & .08 & .31 & .16 & & .62 & .06 \\
5. Considerate Action & 4 & 3.30 & 0.71 & .58 & .58 & .14 & .44 & .16 & .42 & & .30 \\
6. Instinctive Action & 3 & 3.21 & 0.78 & .42 & .45 & .33 & .30 & .24 & .04 & .15 & \\
\hline
\end{tabular}

Note. $k, M, S D, \alpha$, and $\lambda_{6}$ are used to represent the number of items in the subscale, mean, standard deviation, Cronbach's reliability coefficient, and Guttman's 6th reliability coefficient, respectively. Raw correlations are below the diagonal, corrected correlations above the diagonal.

The reliabilities for all but two subscales (Considerate Action and Instinctive Action) are of reasonable magnitude; the reliability of Considerate Action is poor, and the reliability of Instinctive Action is unacceptable. Considering that the Instinctive Action consists of three items only and that the reliability coefficient depends on the number of items, we considered its scores acceptable for the subsequent second-order analysis but not for use in assessment. Correlations between the subscales should be of low to moderate size in order to show discriminant validity. All raw correlations were below .46, but Considerate Action and Assertive Action, as well as Considerate Action and Seeking Social Support, respectively, showed correlations adjusted for item overlap higher than .60.

\section{Second-Order Factors Analysis}

The second aim of the study was to verify whether the structure of SACS-PL reproduces the Multiaxial Model of Coping. For this purpose we conducted the Confirmatory Factor Analysis by fitting two models based on the research review: the three-factor model (Active Prosocial with Seeking Social Support and Considerate Action; Active Antisocial with Dominating Action and Instinctive Action; Active-Passive with Avoidance and Assertive Action) and the two-factor model (Active-Passive with Avoidance and Assertive Action; ProsocialAntisocial with Considerate Action, Seeking Social Support, and Dominating 
Action). The goodness-of-fit indexes for the three-factor model were poor $(\mathrm{CMIN}(7)=127.95, p<.001, \mathrm{CMIN} / \mathrm{DF}=18.28, \mathrm{CFI}=.88, \mathrm{TLI}=.73, \mathrm{RMSEA}$ $\left.=.13,95 \% \mathrm{CI}_{\mathrm{RMSEA}}[.11, .15], \mathrm{SRMR}=.07\right)$, and factor loadings of Instinctive Action, Avoidance, and Assertive Action were less than .50. The two-factor model fit was even worse $(\mathrm{CMIN}(4)=174.83, p<.001, \mathrm{CMIN} / \mathrm{DF}=43.71$, $\left.\mathrm{CFI}=.78, \mathrm{TLI}=.46, \mathrm{RMSEA}=.20,95 \% \mathrm{CI}_{\mathrm{RMSEA}}[.18, .23], \mathrm{SRMR}=.09\right)$, with all loadings less than .50 .

Therefore, in order to explore the second-level structure of the SACS-PL, we conducted an exploratory factor analysis (EFA; minimum residuals method) with varimax rotation. The analysis yielded three factors (as indicated by parallel analysis), accounting for $50 \%$ of the variance (see Table 4 ). The first factor, accounting for $16 \%$ of the variance, can be described as active-antisocial coping. It comprised Dominating Action, Assertive Action, and Instinctive Action. The second factor, accounting for $15 \%$ of the variance, can be described as avoidance, consisting of Avoidance. The third factor, accounting for $19 \%$ of the variance, can be described as active prosocial coping because as containing Seeking Social Support, Considerate Action, and Assertive Action.

Table 4. Results of the Second-order Exploratory Factor Analysis of SACS-PL $(N=1,042)$

\begin{tabular}{lccc}
\hline \multicolumn{1}{c}{ Subscale } & Factor 1 & Factor 2 & Factor 3 \\
\hline Dominating Action & $\mathbf{. 5 6 7}$ & -.290 & -.065 \\
Assertive Action & $\mathbf{. 5 4 8}$ & .080 & $-\mathbf{. 5 2 5}$ \\
Avoidance & .261 & -.899 & -.113 \\
Seeking Social Support & -.008 & -.104 & $\mathbf{- . 6 2 3}$ \\
Considerate Action & .175 & -.046 & $\mathbf{- . 6 6 2}$ \\
Instinctive Action & $\mathbf{. 5 1 4}$ & -.112 & -.061 \\
\hline
\end{tabular}

Note. Factor loadings greater than .40 are bolded.

The results of the second-order analysis deviate from the original model because Assertive Action plays a different role in the SACS-PL structure than expected. It does not counterbalance Avoidance but has gained strong factor loadings in both prosocial and antisocial factors. Therefore, self-reliance, in the examined context, is not an asocial strategy, but it is a component of both prosocial and antisocial strategies. Thus, Avoidance becomes not just a pole of the active-passive axis, but rather an independent asocial strategy. Nevertheless, the Polish adaptation clearly distinguishes groups of active antisocial and prosocial strategies as well as an avoidant strategy, which is in line with the model's assumptions. 


\section{Relationship Between Coping Strategies and Personal Maladjustment}

The validity of the SACS-PL was examined by analyzing the relationship between strategies and personal adjustment. Personal maladjustment was measured using the RISB, which is not based on the respondent's self-report, but on the assessment of statements by the diagnostician.

Based on the review of studies dealing with the relationship between coping strategies and personal adjustment, we expected that (1) there would be a positive relationship between personal maladjustment and avoidant forms of coping; and, in particular, that (2) active prosocial coping strategies would correlate negatively with maladjustment. Because the Multiaxial Model of Coping proposes a more communal perspective of coping and extends the individualistic, maleoriented perspective, it was further predicted that (3) prosocial coping would be more strongly associated with adaptation among women than male participants.

Multilevel regression was used to predict maladjustment based on coping strategies. Eleven groups at risk of social exclusion were included in the analysis as a random effect. Coping strategies, gender, and interactions of each strategy with gender were introduced as fixed effects. Insignificant predictors were removed from the saturated model. The final model, best fitted to the data, is presented in Table 5.

Table 5. Results of Multilevel Regression of Maladjustment on Coping Strategies and Gender $(N=1,042)$

\begin{tabular}{lccccc}
\hline \multicolumn{1}{c}{ Variable } & $B$ & $S E$ & $t$ & $d f$ & $p$ \\
\hline Intercept & 119.44 & 8.57 & 13.94 & 882.89 & .001 \\
Gender & 13.52 & 5.11 & 2.65 & 972.18 & .008 \\
Dominating Action & 1.48 & 0.92 & 1.62 & 972.66 & .106 \\
Assertive Action & -2.83 & 0.97 & -2.90 & 968.07 & .004 \\
Avoidance & 4.94 & 0.92 & 5.35 & 971.38 & $<.001$ \\
Seeking Social Support & -4.02 & 0.86 & -4.64 & 974.43 & $<.001$ \\
Considerate Action & 3.19 & 2.37 & 1.35 & 967.31 & .177 \\
Instinctive Action & -0.59 & 0.75 & -0.79 & 967.08 & .430 \\
Gender $\times$ Considerate Action & -4.01 & 1.50 & -2.68 & 967.09 & .008 \\
\hline
\end{tabular}

Note. $B, S E, t, d f$, and $p$ are used to represent the regression coefficient, its standard error, Student's test statistics, its degrees of freedom, and $p$-value, respectively. 
The overall model predicting maladjustment revealed a total explanatory power (conditional $R^{2}$ ) of $18.34 \%$, where fixed effects explain $10.08 \%$ of the variance (marginal $R^{2}$ ). The variables that are important in explaining maladjustment were: gender interaction with Considerate Action, gender, Assertive Action, Avoidance, and Seeking Social Support. Considerate Action was associated negatively with maladjustment in men $(B=-5.13, p<.001)$ but not in women $(B=-0.97, p=.393)$. The men showed a lower adaptation level than the women. Assertive Action and Seeking Social Support were negatively associated with maladjustment, while Avoidance was positively associated with it. The results of the analysis confirm the validity of the SACS-PL. Active prosocial strategies are associated with a lower level, and avoidant strategies are associated with a higher level of intrapsychic conflicts.

\section{CONCLUSIONS}

This study was intended to arrive at an adaptation of the SACS to the Polish cultural context. To this end, we conducted a survey on 11 samples of people at risk of social exclusion. As such, the total studied group constituted a very broadbased and diverse overall sample. As a result, we obtained a reliable and valid measurement of coping based on the Multiaxial Model of Coping (Dunahoo et al., 1998; Hobfoll, 1998). The structure of the SACS-PL differs from the original. The first-level structure of the scale consists of six subscales, with the reliability of one of them being too low to be useful in practice. The most important differences relative to the original are the separation of Dominating Action (which is a combination of Antisocial Action and Indirect Action), Considerate Action (which is a combination of Cautious Action and Social Joining), and the absence of Aggressive Action, Social Joining, and Indirect Action (not reproduced). We reproduced all the factors identified as relatively culturally stable by Bartczuk et al. (2020). This result demonstrates above all the legitimacy and need for a complete cultural adaptation of the SACS in Polish, similarly to other European studies (Buchwald \& Schwarzer, 2003; Pérez et al., 2012; Schwarzer et al., 2003).

The second-level structure of the SACS-PL also diverges from the model's expectations. The primary difference is the emergence of avoidant coping as the only asocial strategy and the incorporation of Assertive Action in both prosocial and antisocial active coping. These differences may primarily reflect intercultural differences. It seems that Assertive Action or Self-Reliance are not perceived as 
socially neutral in Poland, but instead they are associated either with prosocial or antisocial action. It should be noted that this is so despite Polish Assertive Action being more saturated with aggressiveness and instinctivity than the original Assertive Action. From the perspective of Poles, acting with self-reliance is linked to social context. This connection may be related to a higher degree of collectivism in Poles in comparison with Americans and a higher degree of uncertainty avoidance (Hofstede, 2013; Komor \& Schumann, 2015; Minkov \& Hofstede, 2014; Nasierowski \& Mikula, 1998). It displays a rule-oriented inflexibility when faced with new or ambiguous circumstances (Franke et al., 1991); thus, in this context, any action may be subject to ethical judgment concerning others. The effect of the culture can also be reinforced by the context of social exclusion risk, which the subjects were exposed to. The obtained results also raise questions about the status of the Avoidance subscale in the SACS-PL: Is this an indicator of the first- or second-order factor? Does this follow from the culture or from the specific situation of social marginalization, in which avoidance strategies become valid and autonomous? Further investigation is needed to resolve these issues. Nevertheless, in the SACS-PL factors reflecting active antisocial and prosocial strategies plus an avoidant strategy were distinguished, which confirmed structural validity at a basic level.

The results confirmed the theoretical validity of SACS-PL. We confirmed the relationship between maladjustment and avoidance and prosocial coping strategies, but failed to confirm a more substantial function of prosocial strategies in women than men. Based on our study we are not able to determine whether this is due to the Polish culture or the specific character of the sample. Besides, the weakness of the study lies in its use of only one method to assess validity, and studies using more indicators of (mal)adjustment are needed. Therefore, evidence for the validity of the SACS-PL should be regarded as preliminary. Nevertheless, the SACS-PL is an instrument with acceptable psychometric properties, and we thought that its application in research would elucidate the important aspects of coping in the Polish population, and particularly in marginalized groups that are not addressed by other, more individually oriented measures.

\section{REFERENCES}

Arbuckle, J. L. (2016). Amos (Version 24.0.0) [Computer software]. IBM SPSS.

Bartczuk, R. P., Chwaszcz, J., Hobfoll, S. E., Niewiadomska, I., \& Gałkowska-Bachanek, M. (2020). Is the structure of the Strategic Approach to Coping Scale cross-culturally stable? 
Evidence based on a scoping literature review. Roczniki Psychologiczne/Annals of Psychology, 23(1), 7-21.

Bernat, A., \& Krzyszkowska, M. (2017). Znaczenie i sposoby wykorzystania psychospołecznych zasobów zaradczych w ujęciu S. E. Hobfolla [The meaning and uses of psychosocial coping resources in S. E. Hobfoll's view]. Studia Paradyskie, 27, 255-278.

Buchwald, P., \& Schwarzer, C. (2003). The exam-specific strategic approach to coping scale and interpersonal resources. Anxiety, Stress \& Coping, 16(3), 281-291. https://doi.org/10.1080/ 1061580031000095434

Carver, C. S., Scheier, M. F., \& Weintraub, J. K. (1989). Assessing coping strategies: A theoretically based approach. Journal of Personality and Social Psychology, 56(2), 267-283. https://doi.org/10.1037/0022-3514.56.2.267

Chodak, M., \& Barwiński, Ł. (2010). Autoagresja jako forma radzenia sobie ze stresem—Badania własne [Self-aggression as a form of coping with stress-A research report]. Psychiatria i Psychoterapia, 6(1), 31-46.

Chwaszcz, J., Bartczuk, R. P., \& Niewiadomska, I. (2019). Analiza strukturalna zasobów u osób zagrożonych marginalizacją społeczną-Kwestionariusz Zachowania Zasobów Hobfolla [Structural analysis of resources in those at risk of social marginalization-Hobfoll's Conservation of Resources Evaluation]. Przeglad Psychologiczny, 62(1), 167-202.

Chwaszcz, J., Wiechetek, M., \& Przybyłek, A. (2016). Coping strategies and the risk of developing Internet addiction in young people-A study report. In B. Lelonek \& J. Chwaszcz (Eds.), Gambling and Internet addictions-Epidemiology and treatment (pp. 101-107). Natanaleum Association Institute for Psychoprevention and Psychotherapy.

Crăciun, B., Craiovan, P. M., \& Crăciun, A. (2015). Perceived Stress and Strategic Approach to Coping among Health Professionals in Private Practice. Procedia - Social and Behavioral Sciences, 187, 374-378. https://doi.org/10.1016/j.sbspro.2015.03.070

Drapeau, M., Blake, E., Dobson, K. S., \& Körner, A. (2017). Coping strategies in major depression and over the course of cognitive therapy for depression. Canadian Journal of Counselling and Psychotherapy / Revue Canadienne de Counseling et de Psychothérapie, 51(1), 18-39.

Dunahoo, C. L., Hobfoll, S. E., Monnier, J., Hulsizer, M. R., \& Johnson, R. (1998). There's more than rugged individualism in coping. Part 1: Even the lone ranger had Tonto. Anxiety, Stress, \& Coping, 11(2), 137-165. https://doi.org/10.1080/10615809808248309

Finklestein, M., Laufer, A., \& Solomon, Z. (2012). Coping strategies of Ethiopian immigrants in Israel: Association with PTSD and dissociation. Scandinavian Journal of Psychology, 53(6), 490-498. https://doi.org/10.1111/j.1467-9450.2012.00972.x

Folkman, S. (1997). Positive psychological states and coping with severe stress. Social Science \& Medicine, 45(8), 1207-1221. https://doi.org/10.1016/S0277-9536(97)00040-3

Franke, R. H., Hofstede, G., \& Bond, M. H. (1991). Cultural roots of economic performance: A research note. Strategic Management Journal, 12(S1), 165-173. https://doi.org/10.1002/ smj.4250120912

Geller, P. A., Hobfoll, S. E., \& Dunahoo, C. L. (2009). Women's coping: Communal versus individualistic orientation. In C. L. Cooper, J. C. Quick, \& M. Schabracq (Eds.), International handbook of work and health psychology (3rd ed., pp. 353-382). Wiley-Blackwell.

Grech, L. B., Kiropoulos, L. A., Kirby, K. M., Butler, E., Paine, M., \& Hester, R. (2018). Target Coping Strategies for Interventions Aimed at Maximizing Psychosocial Adjustment in People with Multiple Sclerosis. International Journal of MS Care, 20(3), 109-119. https://doi.org/ 10.7224/1537-2073.2016-008 
Harrel Jr, F. E., \& with contributions from Ch. Dupont and many others. (2018). Hmisc: Harrell Miscellaneous (Version 4.1-1) [R]. https://CRAN.R-project.org/package=Hmisc

Heffer, T., \& Willoughby, T. (2017). A count of coping strategies: A longitudinal study investigating an alternative method to understanding coping and adjustment. Plos One, 12(10), e0186057. https://doi.org/10.1371/journal.pone.0186057

Hobfoll, S. E. (1998). Stress, culture, and community: The psychology and philosophy of stress. Plenum Press.

Hobfoll, S. E. (2006). Stres, kultura i społeczność: Psychologia i filozofia stresu [Stress, culture and community. The psychology and philosophy of stress] (M. Kacmajor, Trans.). Gdańskie Wydawnictwo Psychologiczne.

Hobfoll, S. E., Dunahoo, C. L., Ben-Porath, Y., \& Monnier, J. (1994). Gender and coping: The dual-axis model of coping. American Journal of Community Psychology, 22(1), 49-82. https://doi.org/10.1007/BF02506817

Hobfoll, S. E., Geller, P., \& Dunahoo, C. L. (2003). Women's coping: Communal versus individualistic orientation. In M. Schabracq, J. A. M. Winnubst, \& C. L. Cooper (Eds.), The handbook of work and health psychology (2nd ed., pp. 237-257). J. Wiley \& Sons.

Hofstede, G. (2013). Culture's consequences: Comparing values, behaviors, institutions, and organizations across nations. Sage.

Jachowicz, N., Niewiadomska, I., \& Bartczuk, R. (2015). Sense of support and stress coping strategies in nicotine-dependent persons. In J. Chwaszcz \& I. Niewiadomska (Eds.), Meaning of resources in social inclusion (pp. 80-90). Natanaleum Association Institute for Psychoprevention and Psychotherapy.

Jaworowska, A., \& Matczak, A. (2003). RISB-Test Niedokończonych Zdań Rottera [RISB Rotter Incomplete Sentences Blank]. Pracownia Testów Psychologicznych Polskiego Towarzystwa Psychologicznego.

Jaworowska, A., \& Matczak, A. (2012). RISB—Test Niedokończonych Zdań Rottera: Polskie normalizacje [RISB—Rotter Incomplete Sentences Blank: Polish normalizations]. Pracownia Testów Psychologicznych Polskiego Towarzystwa Psychologicznego.

Kaliampos, A., \& Roussi, P. (2017). Religious beliefs, coping, and psychological well-being among Greek cancer patients. Journal of Health Psychology, 22(6), 754-764. https://doi.org/10.1177/1359105315614995

Knowles, S. R., Austin, D. W., Sivanesan, S., Tye-Din, J., Leung, C., Wilson, J., Castle, D., Kamm, M. A., Macrae, F., \& Hebbard, G. (2017). Relations between symptom severity, illness perceptions, visceral sensitivity, coping strategies and well-being in irritable bowel syndrome guided by the common sense model of illness. Psychology, Health \& Medicine, 22(5), 524 534. https://doi.org/10.1080/13548506.2016.1168932

Komor, M., \& Schumann, J. (2015). Zróżnicowania kulturowe między Polską a Niemcami według wymiarów kultury Hofstede [Cultural differences between Poland and Germany according to Hofstede's dimensions of culture]. Gospodarka Narodowa, 1, 83-102.

Kozhukhar, G. (2017). Psychosocial adaptation, interpersonal relations and coping-strategies in University students. Research Communications in Psychology, Psychiatry and Behavior, 3(1), $1-8$.

Łącka, I., Niewiadomska, I., \& Palacz-Chrisidis, A. (2015). Personality and stress coping strategies in gambling-addicted persons. In J. Chwaszcz \& I. Niewiadomska (Eds.), Meaning of resources in social inclusion (pp. 91-102). Natanaleum Association Institute for Psychoprevention and Psychotherapy. 
Levy, D. J., Heissel, J. A., Richeson, J. A., \& Adam, E. K. (2016). Psychological and biological responses to race-based social stress as pathways to disparities in educational outcomes. American Psychologist, 71(6), 455-473. https://doi.org/10.1037/a0040322

Łosiak, W. (2008). Resource loss, coping, alcohol expectancies and drinking in students. Polish Psychological Bulletin, 39(3). https://doi.org/10.2478/v10059-008-0016-5

Makowski, D. (2018). The psycho package: An efficient and publishing-oriented workflow for psychological science. The Journal of Open Source Software, 3(22), 470. https://doi.org/|$10.21105 /$ joss.00470

Minkov, M., \& Hofstede, G. (2014). A replication of Hofstede's uncertainty avoidance dimension across nationally representative samples from Europe. International Journal of Cross Cultural Management, 14(2), 161-171. https://doi.org/10.1177/1470595814521600

Monnier, J., Hobfoll, S. E., Dunahoo, C. L., Hulsizer, M. R., \& Johnson, R. (1998). There's more than rugged individualism in coping. Part 2: Construct validity and further model testing. Anxiety, Stress, \& Coping, 11(3), 247-272. https://doi.org/10.1080/10615809808248314

Monnier, J., Hobfoll, S. E., \& Stone, B. K. (1996). Coping, resources, and social context. In W. Battmann \& S. Dutke (Eds.), Processes of the molar regulation of behavior (pp. 189-204). Pabst Science Publishers.

Nasierowski, W., \& Mikula, B. (1998). Culture dimensions of Polish managers: Hofstede's indices. Organization Studies, 19(3), 495-509. https://doi.org/10.1177/017084069801900306

Niewiadomska, I., Jakimowicz, E., \& Augustynowicz, W. (2016). Adult Children of Divorce (ACOD) - personal adjustment and preferred coping strategies. In I. Niewiadomska \& W. Augustynowicz (Eds.), Inclusion-Psychosocial aspects (pp. 44-56). Natanaelum Association Institute for Psychoprevention and Psychotherapy.

Osowiecki, D. M., \& Compas, B. E. (1999). A Prospective Study of Coping, Perceived Control, and Psychological Adaptation to Breast Cancer. Cognitive Therapy and Research, 23(2), 169180. https://doi.org/10.1023/A:1018779228432

Park, I. J. K., Wang, L., Williams, D. R., \& Alegría, M. (2018). Coping With Racism: Moderators of the Discrimination-Adjustment Link Among Mexican-Origin Adolescents. Child Development, 89(3), e293-e310. https://doi.org/10.1111/cdev.12856

Pérez, E., Germán, M., \& García, A. (2012). Adaptación española de la Escala Multiaxial de Afrontamiento Estratégico (SACS) de Hobfoll. Psicothema, 24(3), 455-460.

Pérez, G., \& Gómez-Maqueo, E. L. (2007). Resultados preliminares de la adaptacion al espanol de la Escala de Estrategias de Afrontamiento. Psicología y Salud, 17(2), 283-290. Academic OneFile.

Pietras, P., Niewiadomska, I., \& Palacz-Chrisidis, A. (2015). Personal adjustment and preferences for coping strategies in people with behavioural addictions. In J. Chwaszcz \& I. Niewiadomska (Eds.), Meaning of resources in social inclusion (pp. 103-113). Natanaleum Association Institute for Psychoprevention and Psychotherapy.

Pinheiro, J., Bates, D., DebRoy, S., Sarkar, D., \& R Core Team. (2018). nlme: Linear and Nonlinear Mixed Effects Models (Version 3.1-137) [R]. https://CRAN.R-project.org/ package $=$ nlme

R Core Team. (2018). R: A Language and Environment for Statistical Computing (Version 3.5.1) [R]. R Foundation for Statistical Computing. https://www.R-project.org/

Revelle, W. (2018). psych: Procedures for Personality and Psychological Research (Version 1.8.4) [R]. https://CRAN.R-project.org/package=psych 
Rotter, J. B., Lah, M. I., \& Rafferty, J. E. (1992). Rotter Incomplete Sentences Blank (RISB) manual. The Psychological Corporation: Harcourt Brace \& Company.

Schwarzer, C., Starke, D., \& Buchwald, P. (2003). Towards a theory-based assessment of coping: The German adaptation of the Strategic Approach to Coping Scale. Anxiety, Stress \& Coping, 16(3), 271-280. https://doi.org/10.1080/1061580031000095425

Seffren, V., Familiar, I., Murray, S. M., Augustinavicius, J., Boivin, M. J., Nakasujja, N., Opoka, R., \& Bass, J. (2018). Association between coping strategies, social support, and depression and anxiety symptoms among rural Ugandan women living with HIV/AIDS. AIDS Care, 30(7), 888-895. https://doi.org/10.1080/09540121.2018.1441969

Smith, G. D., \& Yang, F. (2017). Stress, resilience and psychological well-being in Chinese undergraduate nursing students. Nurse Education Today, 49, 90-95. https://doi.org/10.1016/ j.nedt.2016.10.004

Timmerman, M. E., \& Lorenzo-Seva, U. (2011). Dimensionality assessment of ordered polytomous items with parallel analysis. Psychological Methods, 16(2), 209-220. https://doi.org/10.1037/a0023353

Tyrka, R., Niewiadomska, I., \& Bartczuk, R. (2015). The severity of crisis in valuation and the use of coping strategies in prison inmates. In J. Chwaszcz \& I. Niewiadomska (Eds.), Meaning of resources in social inclusion (pp. 80-90). Natanaleum Association Institute for Psychoprevention and Psychotherapy.

Zadeh, S. E., Radfar, M., \& Tabrizi, F. M. (2018). Evaluating the Effect of Group Therapy Based on Coping Strategies in Mental Adjustment of Women with Gynecologic Cancer. Journal of Research in Medical and Dental Science, 6(2), 311-316. 